\title{
Article \\ Blockchain Software Selection as a Fuzzy Multi-Criteria Problem
}

\author{
Galina Ilieva $^{1,2, * \mathbb{D}}$, Tania Yankova ${ }^{1}\left(\mathbb{D}\right.$, Irina Radeva $^{2}$ and Ivan Popchev ${ }^{2}$ \\ 1 Department of Management and Quantitative Methods in Economics, University of Plovdiv Paisii \\ Hilendarski, 4000 Plovdiv, Bulgaria; tsvl@uni-plovdiv.bg \\ 2 Intelligent Systems Department, Institute of Information and Communication Technologies, \\ 1113 Sofia, Bulgaria; irina.radeva@iict.bas.bg (I.R.); ivan.popchev@iict.bas.bg (I.P.) \\ * Correspondence: galili@uni-plovdiv.bg
}

Citation: Ilieva, G.; Yankova, T.; Radeva, I.; Popchev, I. Blockchain Software Selection as a Fuzzy Multi-Criteria Problem. Computers 2021, 10, 120. https://doi.org/ 10.3390/computers10100120

Academic Editor: Nabil El Ioini

Received: 16 August 2021

Accepted: 22 September 2021

Published: 24 September 2021

Publisher's Note: MDPI stays neutral with regard to jurisdictional claims in published maps and institutional affiliations.

Copyright: (c) 2021 by the authors. Licensee MDPI, Basel, Switzerland. This article is an open access article distributed under the terms and conditions of the Creative Commons Attribution (CC BY) license (https:// creativecommons.org/licenses/by/ $4.0 /)$.

\begin{abstract}
Increased consumer requirements for quality, safety and traceability of goods in supply chains has accelerated the implementation of blockchain during the COVID-19 pandemic. The right choice of blockchain software is a complicated task and an important prerequisite for successful deployment. In this study, we propose a conceptual framework for group multi-criteria selection of blockchain software in fuzzy environment according to organization needs and experts' judgements. The applicability of the new framework has been verified through an illustrative example for ranking blockchain systems. The evaluations of compared alternatives were calculated by using measurement of alternatives and ranking according to the compromise solution (MARCOS) method. The robustness of the new framework was proven by sensitivity analysis in which two (crisp and fuzzy) MARCOS models with two different sets of weighting coefficients were compared.
\end{abstract}

Keywords: blockchain; agriculture 4.0; multi-criteria decision-making; smart contracts; fuzzy sets; internet of things; big data

\section{Introduction}

In the second half of the 20th century, information and communication technologies (ICT) were introduced in plant growing in order to increase food production. As a result, agriculture productivity has increased, enabling farmers to produce plentiful food in many parts of the world [1-3]. Blockchain is one of the promising information technologies in agriculture, which allow accessing, tracking, monitoring and analyzing crop data. Relying on this technology, quality of agricultural goods increases, while costs of their production decrease. Digital smart contracts, built upon a secure distributed ledger, automate commercial transactions and remove the friction caused by traditional (paper-based) contracts [4-8].

There is a variety of blockchain and blockchain as a service (BaaS) solutions for automation of commercial transactions and supply chain management. The question then arises: how to select the most appropriate blockchain infrastructure, platform or software for digital assets and transactions in organizations [9]? Factors, such as globalization, cyberattacks, and opportunistic behavior of partners are making blockchain selection a difficult problem, especially in small and medium-sized enterprises [10]. As blockchain technology is novel and complex, there is no unified algorithm, guideline or framework for assessing its applicability and choosing the most suitable blockchain option yet [11,12].

A possible way to evaluate blockchain alternatives is combining criteria or hierarchies of criteria in multi-criteria decision making (MCDM) models. For this purpose, different methods have been devised. For example, analytical hierarchy process (AHP) [13], simple multi-attribute rating technique (SMART) and VIseKriterijumska Optimizacija I Kompromisno Resenje (VIKOR) [14] have been applied solely [15] or in combination such as AHP and VIKOR [16], must-have, should-have, could-have, and wont-have (MoSCoW) 
prioritizing technique and technique for order of preference by similarity to ideal solution (TOPSIS) [17], double normalization-based multiple aggregation (DNMA) and criteria importance through inter-criteria correlation (CRITIC) [18]. A set of several MCDM methods (fuzzy VIKOR, TOPSIS and evaluation based on distance from average solution-EDAS) have been implemented for selecting a data storage platform $[19,20]$.

In light of the abovementioned, we suggest a new conceptual framework for blockchain software selection. Depending on domain, input assessments of alternatives may be processed in different ways. For example, in case of a-priory knowledge about the ideal and anti-ideal solutions, similarity-based methods (multi-attributive border approximation area comparison-MABAC [21], combinative distance-based assessmentCODAS [22] and measurement of alternatives and ranking according to compromise solution-MARCOS [23]) should be preferred. Otherwise, it is preferable that the calculations be made by utility-based methods (such as simple additive weighting-SAW and weighted aggregated sum product assessment-WASPAS [24]). The proposed framework also streamlines group decision-making procedure in case of either crisp or fuzzy values of decision matrix.

Following this, a comparative analysis between crisp and fuzzy multi-criteria methods has been performed. More specifically, we ran an experimental evaluation, in which blockchain users and experts were asked to assess six smart contracts management systems. The evaluation scores were calculated by crisp and fuzzy MARCOS and the obtained results were compared. In order to check the consistency and reliability of the final rankings, we introduced a sensitivity analysis of the MCDM models in blockchain software evaluation.

The goal of our study is to solve several tasks concerning blockchain and its implementation with focus on agriculture: (1) compare the most widely used blockchain platforms; (2) explore the impact of blockchain software on agricultural companies; (3) propose a conceptual framework for multi-criteria selection of an appropriate blockchain software; and (4) verify the proposed framework through an illustrative example.

The rest of this paper is structured as follows: Section 2 starts with some basic characteristics of blockchain technology, describes main peculiarities of the most widely used blockchain platforms, continues with agriculture case studies and finally, presents and compares agricultural blockchain software. Section 3 outlines the new framework for ranking of blockchain software and briefly presents MCDM methods for aggregation of criteria values. Section 4 verifies the new framework by crisp and fuzzy decision models and evaluates the effectiveness and usefulness of the new methodology to address the problem for blockchain system selection. The results show that our framework recommends suitable solutions, and does so efficiently, without complicated calculations. Finally, the last section summarizes the proposed approach, emphasizing its novelty and outlining directions for future research.

\section{Blockchain Technology and Its Applications in Agriculture}

Blockchain as a tool for data gathering and processing is a cornerstone for successful digital transformation. However, managers and other stakeholders are still not familiar with this technology's capabilities in automating commercial transactions and enhancing supply chain management. In this section, basic characteristics of blockchain technology are presented, then the most widely used blockchain platforms are compared and applications of blockchain in agriculture are analyzed.

\subsection{Blockchain Basics}

Blockchain is a system in which a growing sequential list of records (represented by blocks) are linked using cryptographic algorithms. Each block contains a cryptographic hash of the previous block, a timestamp and transaction data. This distributed database holds records of all transactions or digital events that have been executed and shared among participating parties $[5,25,26]$. 
Unlike classical information systems, in which centralized databases are controlled only by authorized representatives of an organization, in blockchain systems no one can independently and unilaterally alter data. Blockchain technology guarantees data irreplaceability and immutability. This ensures the authenticity and unchangeability of both the transactions recorded in the blockchain system, and stored data (digital assets, contracts or other documents). As blockchain acts as a common register of operations, this technology becomes very convenient for recording events (for example, in quality assurance and trading deals) and data operations (in identity management and product authentication in a supply chain) $[27,28]$.

Blockchain technology is suitable for implementation in financial services sector, for it successfully digitizes three traditional operations: authentication of participants, registration of transactions and conclusion of contracts [29]. Accurate data provided by blockchain systems can also become input in artificial intelligence applications [30].

To summarize, blockchain technology creates a public ledger for distributed historical transactions to prevent tampering and fraud attempts. Each interaction is documented in a P2P database that relies on the previous, time-stamped record to verify and execute an exchange. Blockchain technology can be successfully implemented as a reliable storage of digital assets across a variety of industries including agribusiness.

\subsection{The Peculiarities of Major Blockchain Platforms}

In this section, the main features of the most widely used blockchain platforms (Corda, Ethereum, Hyperledger Fabric, NEO and Ripple) are briefly described.

Corda (https: / / www.corda.net, accessed on 21 September 2021) utilizes distributed ledger software. It operates on permissioned network and therefore, allows only an authorized group of users to access crucial data. It is an open-source blockchain platform designed by the financial industry, but today this platform has its implications in various sectors such as supply chain and public administration. Corda can be employed in reducing transaction costs and streamlining business operations.

Ethereum (https: / / ethereum.org, accessed on 21 September 2021) is an open-source blockchain platform for smart contracts on a custom-built network. Ethereum is a decentralized software technology, and it can be used to codify, decentralize, secure and trade. Ethereum enables distributed applications (DApps) to be created without any downtime, fraud, control or interference from any third party. DApps utilize smart contracts and run on the Ethereum virtual machine. Some examples include micro-payments platforms, reputation functions, online gambling applications, schedulers and P2P marketplaces. Ethereum has its own native programming language (Solidity) for DApps development and deployment. The platform allows enterprises to create private permissioned networks according to their specific needs. The platform's users have to pay charges in ethers for executing transactions and running apps.

Hyperledger Fabric (https: / / www.hyperledger.org, accessed on 21 September 2021) is an open-source blockchain platform, managed by Linux Foundation. It is an umbrella project with several frameworks and protocols. Hyperledger is a permissioned blockchain that accelerates industry-wide collaboration for development of high performance and reliable distributed ledger technology-based framework. It can be used in many industries for operational improvement and is currently the most common platform for B2B businesses. Hyperledger supports account model and unspent transaction output (UTXO) for smart contracts. The platform does not have any built-in cryptocurrency.

NEO (https:/ / neo.org, accessed on 21 September 2021) is a blockchain platform designed for a scalable permissioned network. NEO employs the delegated Byzantine Fault Tolerance (dBFT) consensus algorithm, which brings better scalability and performance in comparison with other consensus mechanisms. In NEO SmartContract system, developers can program smart contracts in Go, Java, Python, C\# or other high-level programming language.

Ripple (www.ripple.com, accessed on 21 September 2021) includes real-time gross settlement system, currency exchange and digital payment network for financial transactions. 
This blockchain platform connects banks, organizations, and assets exchanges and focuses on fast payment processing. The cryptocurrency used on the Ripple network to transfer money between different currencies is denoted as XRP.

Table 1 provides a summary of the abovementioned blockchain platforms and their main characteristics (governance, platform description, mode of operation, consensus algorithm, cryptocurrency and smart contracts). These features can be built into evaluation systems for selection of blockchain platforms and their components.

Table 1. Comparison of major blockchain platforms.

\begin{tabular}{|c|c|c|c|c|c|}
\hline $\begin{array}{l}\text { Platform } \\
\text { Feature }\end{array}$ & Corda & Ethereum & Hyperledger Fabric & NEO & Ripple \\
\hline Governance & $\mathrm{R} 3$ & $\begin{array}{l}\text { Ethereum } \\
\text { Developers }\end{array}$ & $\begin{array}{c}\text { Linux } \\
\text { Foundation }\end{array}$ & $\begin{array}{l}\text { Neo Smart } \\
\text { Economy }\end{array}$ & Ripple Labs \\
\hline $\begin{array}{l}\text { Platform } \\
\text { Description }\end{array}$ & Finance industry & $\begin{array}{c}\text { Generic } \\
\text { framework }\end{array}$ & $\begin{array}{l}\text { Modular } \\
\text { framework }\end{array}$ & $\begin{array}{c}\text { Generic } \\
\text { framework }\end{array}$ & $\begin{array}{l}\text { Decentralized } \\
\text { financial tool }\end{array}$ \\
\hline $\begin{array}{l}\text { Mode of } \\
\text { Operation }\end{array}$ & $\begin{array}{l}\text { Permissioned node } \\
\text { network, private }\end{array}$ & $\begin{array}{c}\text { Permissionless node } \\
\text { network, public or } \\
\text { private }\end{array}$ & $\begin{array}{l}\text { Permissioned node } \\
\text { network, private }\end{array}$ & $\begin{array}{l}\text { Permissioned node } \\
\text { network, private }\end{array}$ & $\begin{array}{l}\text { Permissioned node network } \\
\text { (UNL list) }\end{array}$ \\
\hline $\begin{array}{l}\text { Consensus } \\
\text { Algorithm }\end{array}$ & $\begin{array}{c}\text { Only parties } \\
\text { involved could make } \\
\text { decisions }\end{array}$ & PoW-PoS & $\mathrm{dBFT}$ & dBFT & $\begin{array}{l}\text { XRP Ledger Consensus } \\
\text { protocol }\end{array}$ \\
\hline $\begin{array}{l}\text { Crypto- } \\
\text { currency }\end{array}$ & $\begin{array}{l}\text { No native } \\
\text { cryptocurrency }\end{array}$ & $\begin{array}{l}\text { Ether, ERC-20 } \\
\text { compatible } \\
\text { tokens via smart } \\
\text { contracts }\end{array}$ & $\begin{array}{l}\text { No native } \\
\text { cryptocurrency, } \\
\text { currency and } \\
\text { tokens via chain code }\end{array}$ & $\begin{array}{c}\text { NEO, NEO-5 } \\
\text { compatible } \\
\text { tokens and GAS tokens }\end{array}$ & XRP \\
\hline $\begin{array}{l}\text { Smart } \\
\text { Contracts }\end{array}$ & $\begin{array}{l}\text { Smart contract code } \\
\text { (Kotlin, Java); smart } \\
\text { legal contract }\end{array}$ & $\begin{array}{l}\text { Smart contract code } \\
\text { (Solidity) }\end{array}$ & $\begin{array}{l}\text { Smart contract code: } \\
\text { (Go, Java) }\end{array}$ & $\begin{array}{l}\text { Smart contract code } \\
\text { (C\#, Java, Python, etc.) }\end{array}$ & $\begin{array}{c}\text { XRP Ledger Hooks (any } \\
\text { WebAssembly compatible } \\
\text { language) }\end{array}$ \\
\hline
\end{tabular}

Platform description: The compared frameworks have very different fields of application. Ethereum, Hyperledger Fabric and NEO are industry-independent, while Corda and Ripple's use cases come from financial services sector.

Mode of operation: Corda, Hyperledger Fabric, NEO and Ripple are closed (private) blockchain platforms, while Ethereum is open (public) platform. The drawback of an open blockchain is that its transaction speed is not very high.

Consensus algorithm: The compared platforms employ different consensus mechanism, such as proof of work (PoW), proof of stake (PoS) or distributed Byzantine Fault Tolerance $(\mathrm{dBFT})$. PoW is the older mechanism and it is only available in Ethereum, while PoS and dBFT are newer, faster and more efficient mechanisms.

Cryptocurrency: Blockchain tracks data in smart contracts by using account model and UTXO. The account model is embedded in Ethereum (Ether and ERC-20 compatible tokens), NEO (NEO and NEO-5 compatible tokens) and Ripple (XRP). Corda and Hyperledger Fabric employ UTXO.

Smart Contracts: The list of popular blockchain programming languages includes Solidity (Ethereum), Kotlin (Corda), Java (Corda, Hyperledger Fabric, NEO). Ripple supports smart contracts through any WebAssembly compatible programming language.

Despite the many benefits of blockchain over alternative ways for reliable data storage, this technology has some disadvantages. Blockchain-based applications require all participants in a supply chain to utilize the same platform. This, in turn, implies both technology investments and organizational changes in each business process. While many blockchain solutions, such as Ethereum and Hyperledger Fabric, are open-source software, the cost of blockchain implementation is not low. Blockchain platforms require significant expensesfor project management, hiring developers, licensing in the case of a paid solution and maintenance. In addition, some blockchain platforms consume a lot of energy. For example, PoW consensus algorithm has high energy consumption due to its high time complexity. 


\subsection{Blockchain in Agriculture by Economic Activities}

In this section, we discuss the main application areas of blockchain in agriculturefood supply chain management, land management, trading, electronic commerce, and crop insurance. Agricultural supply chain consists of a set of participants who buy or sell a particular product as it moves from field to table. This chain includes input suppliers, farmers (growers), processors, shipping companies, wholesalers, retailers, and final consumers. The digitization of agricultural supply chain, supported by blockchain technology, is depicted in Figure 1. Every action performed between actors along the food trajectory, empowered by the use of blockchain technology, is represented by an arrow. Each product follows its own way to a customer and every transaction (supplier-farmer, farmer-insurance company, farmer-processing company, farmer-distributor) is recorded in the blockchain [4].

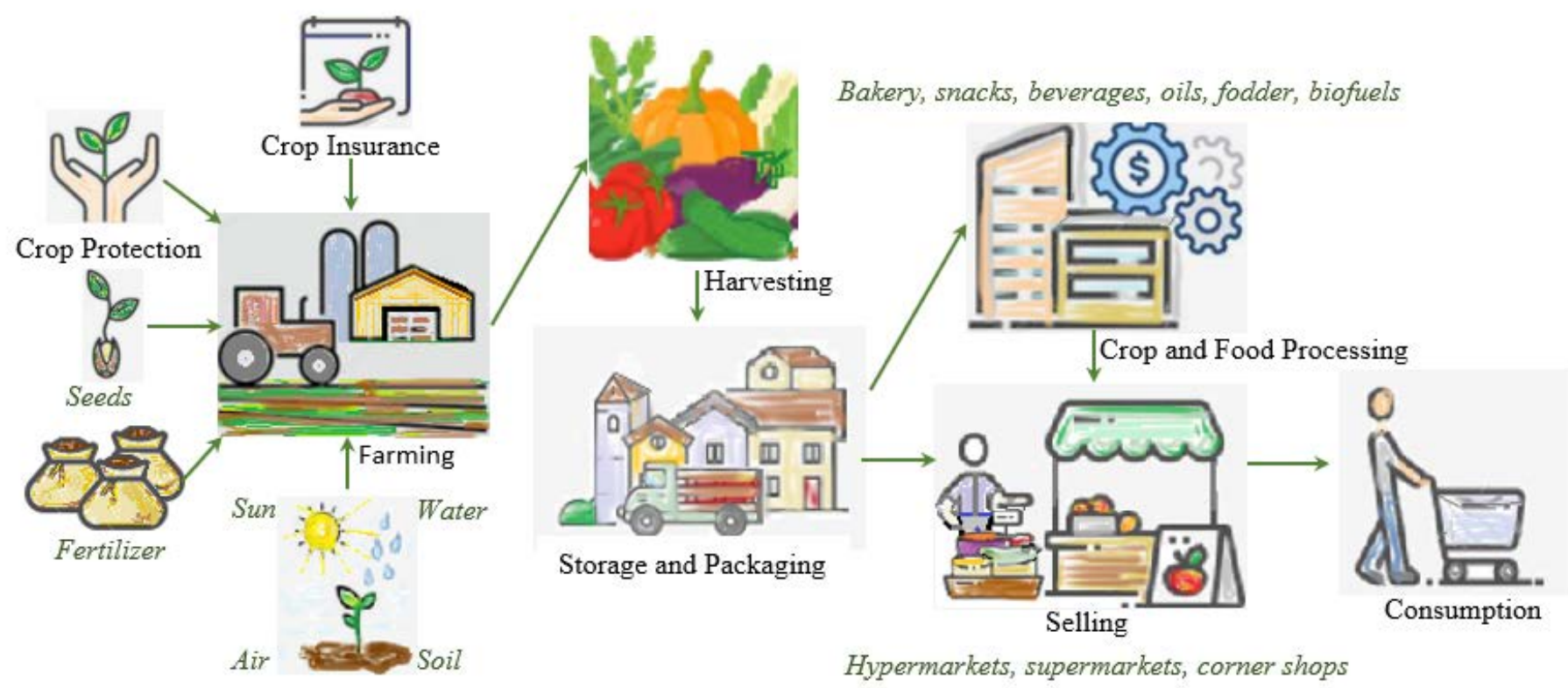

Figure 1. Blockchain in agriculture and food value chain.

Implementing a blockchain platform digitizes the business processes in supply chain and increases the confidence of all participants in it [6,8,31,32]. The imposition of COVID-19 lockdowns has exacerbated tracking food products' origin, resulting in more hazardous food. According to the Global Food Safety Initiative, food retailers across the world are also demanding certifications from suppliers to ensure food safety for every stakeholder in the value chain. Thus, the spread of the COVID-19 pandemic has led to increasing use of blockchain in the food sector from farms to customers for traceability and transparency [33].

Blockchain technology offers an effective tool for land transactions, provides digital documentation to agents in the land rental market and reduces inefficiency in land systems [34]. This technology can build an open agricultural cadaster and banks can reject loans application from customers who have already pledged their land in another bank. A blockchain system can also reduce the time for receiving agricultural subsidies.

Trading agricultural products depends on complex relationships among many participants in the supply chain. Common problems here are payment delays and the presence of substandard goods. Consumers are increasingly concerned about food quality and are interested in whether food safety standards are being met. In order to increase the transparency of business processes, blockchain systems for smart contracts can be implemented. Then, buyers can track the origin of food products, which guarantees their reliability and quality. Retailers and manufacturers eliminate the possibility of substandard products reaching the shelves. The inherent transparence of systems built on blockchain 
minimizes the chances of low-quality products being delivered to stores and false information about them being provided. Blockchain-based systems also reduce the time to investigate complaints $[5,35,36]$.

In electronic commerce of agricultural products, the conclusion of smart contracts in a blockchain environment avoids the need for financial intermediaries, reduces time for processing documents and hence, decreases transaction costs for completing deals. Decentralized blockchain-based electronic exchange services connect buyers and sellers without third parties and related fees. In these cases, trust between users increases due to smart contracts, market security tools, and built-in reputation management [37].

A key issue of establishing smart agriculture is developing a comprehensive security system that facilitates data management. Blockchain technology stores data that various actors has generated throughout the entire value-adding process, from seed to sale, of producing an agricultural good. Through decentralization and encryption, blockchain secures the entire system. It guarantees that data are transparent to the participants and all records are immutable and traceable [7,38].

Blockchain can also contribute to the improvement of index insurance in agriculture in two ways. First, payments are timely and automated according to meteorological data, as set in the smart contract. Second, weather data and data from other sources (such as growth data collected from agricultural machinery), are automatically taken into consideration to reduce risk and hence, indexing is more accurate and insurance payment process is more efficient [39].

In agriculture, blockchain redesigns many existing business processes (tracing food origin, tracking customer demand, settling transactions) to create new marketplaces. Blockchain also transforms the way data are used in agriculture and finally, revolutionizes the whole sector. The main advantages of blockchain applications in agriculture are as follows: (1) food supply chains become reliable and sustainable; (2) risk in terms of quality and quantity of food supply and safety is reduced and thus, trust between agricultural producers and consumers is enhanced; (3) smart contracts guarantee timely payments between stakeholders. By using blockchain technology, agriculture and food industry may build interoperable and robust information systems integrating data capture, identification, and data sharing across supply chain participants in a secure manner.

\subsection{Blockchain Software in Farming}

In this section, we present some basic features of the most widely used blockchain software in agriculture.

Agri-Wallet-Coin22 (Netherlands, 2017, https://agri-wallet.com, accessed on 21 September 2021) provides a financial platform for agricultural value chains worldwide. Through its unique token structure, Agri-Wallet "locks" finance in the value chain so it is not diverted to non-agricultural purposes. It is easy to use and provides real-time insights and financial transparency.

Agri10x (India, 2018, https: / / www.agri10x.com, accessed on 21 September 2021) sets up a blockchain-enabled B2B electronic marketplace that connects farmers with buyers, helping them sell their produce directly. Agri10x works with a massive network of access points across rural India for delivery of e-governance services. According to Agri10x's plans, the virtual marketplace will employ many rural entrepreneurs, contributing to village employment.

AgriChain (Australia, 2015, https: / / agrichain.com, accessed on 21 September 2021) creates an agricultural supply chain platform intended to connect and transfer data between supply chain participants. AgriChain brings together all stakeholders in the agricultural supply chain, allowing them to make informed decisions, eliminate unnecessary paperwork, and reduce supply chain inefficiency and risk.

AgriDigital (Australia, 2015, https://www.agridigital.io/products/agridigital, accessed on 21 September 2021) designs an Ethereum-based blockchain commodity management software that helps process complex agricultural transactions using smart con- 
tracts and simplifies grain supply chains. AgriDigital allows users to digitize all stages of product movement eliminating paper documents. Clients and contractors communicate directly through the platform and payments can be easily made.

AgriLedger (UK, 2016, http:/ / www.agriledger.io, accessed on 21 September 2021) launches a blockchain-based software to integrate agricultural value chain, to improve transparency, to control information flows and to provide financial services. By using AgriLedger's system, farmers have easy access to peer-to-peer dealing.

AgriOpenData (Italy, 2015, https: / / www.agriopendata.it, accessed on 21 September 2021) is a software-platform that supports farmers in traceability and certification of agricultural products by using the blockchain technology and smart contracts. The system allows farmers to make safe and automatic transactions along the supply chain, increases the high-quality production (in particular organic products), improves the environmental sustainability and brings transparency and safety to the final consumer. The integration of open data into the cloud-based platform reduces cost and time for data management, supports farmers in making right decisions on field and provides the necessary documentation.

Ambrosus (Switzerland, 2017, www.ambrosus.io, accessed on 21 September 2021) is a software system that employs blockchain and IoT to track products through supply chain and to guarantee product quality, safety and origin for customers. Ambrosus works with pharmaceutical companies to integrate blockchain-based verification for better control and guarantee the authenticity of raw materials and food products. The system uses a number of different approaches including the prediction of protein, fat, $\mathrm{pH}$, as well as machine learning to define the composition of a final product. New opportunities for paperwork automation between the companies and their corresponding banks are being explored.

Bext360 (US, 2016, https:/ / www.bext360.com, accessed on 21 September 2021) builds measurable accountability for critical supply chains. The SaaS platform allows blockchain traceability and quantifiable measurements for sustainable agribusiness. Bext360 focuses on supply chains such as coffee, seafood, timber, minerals, cotton and palm oil to provide a traceable data from producer to consumer.

Centaur Analytics (US, 2016, www.centaur.ag, accessed on 21 September 2021) combines its Internet-of-Crops software platform, digital twin technology and smart sensors to transform agriproduct supply chains into a global, trusted quality chain. Centaur Token (CNTR) is the value carrier for the Centaur ecosystem.

Demeter (Singapore, 2016, https:/ / demetoken.io, accessed on 21 September 2021) offers entire ecosystem for farmers and consumers. In addition to optimizing the supply chain, the company promotes fair pricing and helps smallholders enter the market. In the implementation of the blockchain platform, Demeter also uses the Internet of things, artificial intelligence, and solutions for system design and data analysis to solve some problems in production, warehousing, logistics, stores, and after-sales of organic food. DEMETOKEN, based on the Ethereum ERC-20, is the core asset of Demeter Ecosystem.

Etherisc (Switzerland, 2016, https: / / etherisc.com, accessed on 21 September 2021) builds a platform for decentralized crop insurance applications. By using blockchain technology, corporates, large and small, not-for-profit groups and insurtech startups provide better products and services, enable lower operational costs and greater transparency into the industry and democratize access to reinsurance.

Investigating how conventional supply chains could be radically improved so producers receive a truly fair share of the deal, FairChain (Netherlands, 2018, https: / fairchain. org /blockchain-info, accessed on 21 September 2021) establishes Moyee Coffee Company for growing premium quality coffee and gives farmers fair deals for their efforts.

By tracking food production events on blockchain-enabled platform, Harvest IDArc-Net (Ireland, 2017, https: / / arc-net.io, accessed on 21 September 2021) reveals products provenance to customers and increases their loyalty and trust in food quality. The platform employs precision farming techniques to track arable and pastoral products through their complete lifecycle from growth to packaging, logistics and retail. By using QR, NFC or other consumer scannable technologies, Arc-Net provides assurance to customers that 
they are purchasing genuine products and through data analytics can identify possible parallel-trading and other grey market practices.

IBM FoodTrust (US, 2017, https: / / www.ibm.com/blockchain/solutions/food-trust, accessed on 21 September 2021) is a network built on IBM Blockchain, designed to connect users in the food supply system and promote traceability. Users can connect to partners and decide what data to share when define their transactions.

Land LayBy (Kenya, 2018, https:/ /hrbe.io, accessed on 21 September 2021) has a trusted shared distributed ledger for recording land buying and selling transactions that can never be altered, corrupted, forged or duplicated by error. Land LayBy uses an Ethereum-based shared ledger to keep records of land transactions.

The OriginTrail (Slovenia, 2016, http:/ / www.origintrail.io, accessed on 21 September 2021) ecosystem guarantees trusted data sharing and supports provenance and sustainability to global supply chains. The system prevents counterfeits and tracks food sources. Trace (TRAC) is an Ethereum-based ERC-20 cryptographic token that enables data operations on the OriginTrail Decentralized Network.

Ripe.io (US, 2017, https: / / www.ripe.io, accessed on 21 September 2021) fosters longlasting trust and confidence in food supply chain through a platform where every participant can access transparent and reliable data on the origin, journey and quality of their food. Ripe.io transforms the food system by working with actors along the food supply chain to create a community in which access to data equals brand integrity, transparency, security and better food for customers.

Starbucks (US, 2019, https:/ /www.microsoft.com, accessed on 21 September 2021) trace the journey that coffee makes from farm to cup and connect the people who drink it with the people who grow it by using blockchain software. Microsoft's Azure Blockchain Service allows supply chain participants to trace both the movement of their coffee and its transformation from bean to final bag. For farmers, the system provides data and visibility once the beans leave their farms. It also allows customers to see the impact their coffee purchase has on the real people they are supporting.

TE-FOOD (Germany, 2016, https: / te-food.com/solution/blockchain, accessed on 21 September 2021) blockchain, TrustChain, enables both supply chain participants and consumer community to maintain network nodes to decentralize traceability information. TE-FOOD is a public-permissioned blockchain. While blockchain data which have an access level set as "public" by the food company can be read publicly on the blockchain explorer, writing data to the blockchain or validating transactions requires permission for additional security.

Trumodity-GrainChain (US, 2017, https: / / www.grainchain.io, accessed on 21 September 2021) is a transaction platform for agricultural industry. Trumodity facilitates prompt payment to producers and suppliers and the immediate availability of tradable commodities to buyers. It eliminates fraud and corruption through certification and accountability while streamlining operating procedures.

Worldcover (US, 2015, https:/ / esa-worldcover.org/en, accessed on 21 September 2021) uses satellite data, on-ground sensors, mobile phone technology, and data analytics, including innovation risk modelling, for creating and delivering its weather index-based insurance products to individual farmers and agribusinesses. Once the rainfall amount has been assessed, payments are sent instantly to farmers through mobile money providers [40].

VeChainThor (China, 2018, https: / / www.vechain.org, accessed on 21 September 2021) is a public blockchain that is designed for mass adoption by enterprises no matter their size. It is intended to serve as the foundation for a sustainable and scalable business ecosystem. VeChainThor blockchain offers a proof-of-authority (PoA) consensus algorithm, meta-transaction features, protocols of transaction fee delegation, on-chain governance mechanism, built-in smart contracts as well as tools for developers.

Depending on their main purpose, the blockchain systems described above, can be divided into four main groups: (1) supply chain applications (AgriChain, AgriDigital, AgriLedger, AgriOpenData, Ambrosus, Bext360, Harvest ID); (2) electronic commerce 
(Agri10x); (3) financial services (Agri-Wallet, Demeter, Trumodity) and (4) crop insurance (Etherics, WorldCover). Some of information systems are industry independent, while others are industry specific, for example AgriDigital—grain production; FairChain, Starbucks-coffee industry. The majority of agribusiness blockchain systems is Ethereumbased, for example AgriDigital, Demeter, Land Layby, OriginTrail. Hyperledger Fabric is the most widely used permissioned blockchain platforms (for example, IBM FoodTrust).

Blockchain technology has various applications in intelligent agriculture. It reorganizes the production chain, the management chain and the transaction chain so that the product life cycle can be easily traced and managed. There are some disadvantages of blockchain technology: (1) there is no unified system for keeping agricultural documentation; (2) blockchain deliveries are much more expensive than traditional deliveries; (3) additional investment is needed for blockchain integration with legacy systems. Despite these drawbacks, blockchain technology provides a multitude of advantages for agricultural companies: controlled data sharing, improved supply chain efficiency, enhanced decision-making process and thus, increased competitiveness.

\section{A New Multiple Criteria Methodology for Blockchain Software Evaluation}

In this section we formulate the blockchain selection as a MCDM problem, present a unified framework for its solution and briefly describe the preferred MCDM methods.

\subsection{New Conceptual Framework for Blockchain Software Selection}

Let $\mid B C_{-}$Alternatives $\mid=N$ and $B C_{-}$Alternatives $=\left\{A_{1}, A_{2}, \ldots, A_{N}\right\}$ be a set of blockchain software products on the market. Moreover, let $\mid B C_{-}$Criteria $\mid=M$ and BC_Criteria $=\left\{C_{1}, C_{2}, \ldots, C_{M}\right\}$ be a set of blockchain criteria (blockchain software features such as a cloud-based platform, Java support, cyberattack resistance). Each $A_{i} \in B C$ _Alternatives, $i=\overline{1, N}$ consists of a subset of $B C_{-}$Criteria. The task is to evaluate and prioritize the options from $B C_{-}$Alternatives according to the values given in decision matrix Evaluations ${ }_{N \times M}$ for each criterion.

The previous section highlighted the importance of choosing a blockchain product tailored to the specific needs of business organizations. The diversity in blockchain platforms and number of available options complicate the process of software and vendor selection for prospective blockchain users and there is a need for a framework for blockchain software selection [41]. Given that each blockchain product could be characterized by using vague assessments for multiple criteria, the core of our new framework should be the fuzzy MCDM approach.

The proposed conceptual framework consists of six steps, described below (Figure 2).

Step 1. Exploring user blockchain software needs

In the first stage of this step, in order to collect data about firm's business model, we apply the questionnaire from Lo et al. [42]. There are many questions listed in the form, for example, multi-party data processing, trusted authority, transaction history, immutable transactions and many other requirements. Next, in the second stage, a Boolean suitability index is calculated as a measure of firm's readiness for blockchain technology deployment. If the index value obtained for a particular organization is true, the company could be considered as suitable for blockchain software adoption, and the selection process can continue to Step 2. Otherwise, it should go to the end of the blockchain software selection process.

Step 2. Development of user requirements specification for blockchain software

In order to collect data about consumer requirements, the questionnaire method is used once again. The questionnaire consists of several question groups, corresponding to the various aspects of distributed network ledger. In case a team of experts or group of customers fills in the questionnaire, their suggestions are summarized. At the end of this step, the basic parameters of blockchain software are defined.

Step 3. Construction of multi-criteria system for blockchain software assessment 
In this step, a multi-criteria index system for blockchain software is established. The proposed dimensions are built on user requirements and importance of blockchain specifications for the company's business model. Other evaluation measures can also be involved in construction of the assessment system. For example, the evaluation indices can also include social and organizational characteristics of the company.

The multi-criteria system can also be expanded with additional technical specifications and socio-economic data from blockchain providers, demo-versions experience or customer reviews from social media.

Step 4. Input of decision matrix and calculation of weighting coefficients

Based on data about the company's business activity, personalized multi-criteria evaluation system, and available datasets for blockchain software comparison, the corresponding assessments are filled in the decision matrix. If there are categorical variables, they are converted into fuzzy numbers. In case the alternatives are evaluated by a group of experts, the decision matrix is filled in with the arithmetic means of their evaluations. After that, the evaluations of each category and each blockchain software feature from the questionnaire (Step 2) are coded. The final values of weighting coefficients are functions of the importance of categories and blockchain features.

Step 5. Multi-criteria decision-making

This step determines the blockchain software ranking using fuzzy multi-attribute decision-making algorithms. In order to eliminate inaccuracies of the solution due to the specifics of input data, several methods are applied. Here we suggest employing five MCDM methods-SAW, WASPAS, MABAC, CODAS and MARCOS.

Step 6. Results' analysis

In the analysis of results, only blockchain applications that have been top ranked with the various MCDM methods are left. In this step, decision-makers select the most suitable blockchain product.

At the end of the algorithm, it is proposed that the blockchain software with the highest potential to improve both the individual aspects and the overall business activity of the enterprise be deployed.

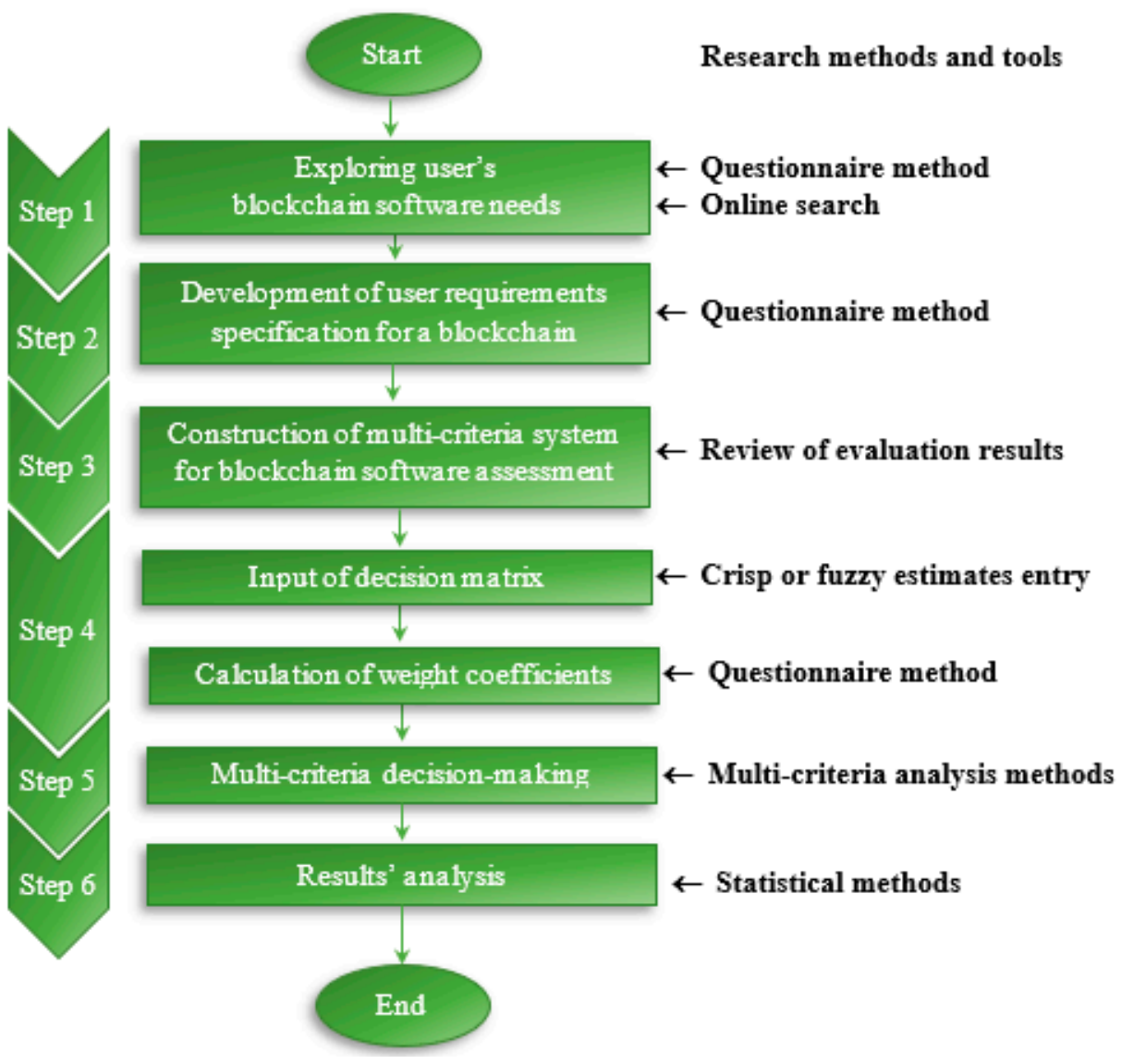

Figure 2. The flowchart of the proposed framework for blockchain software selection. 


\subsection{Decision Making Support for Blockchain Evaluation}

The abovementioned multi-criteria methods belong to two main MCDM groups: (1) multi-attribute utility theory with additive weighted value function (SAW, WASPAS) and (2) similarity/dissimilarity to the best/worst alternatives with distance measures (MABAC, CODAS, MARCOS). The linear transformation in the first group preserves relative ranking of normalized assessments. In the second group, the utility of alternatives depends on their distances to the ideal and negative-ideal solutions for each attribute.

The simple additive weighting (SAW) consists of calculating a utility function $U\left(A_{i}\right)$ for every alternative $A_{i}, i=\overline{1, N}$ and selecting the one with the highest value. The utility function is a linear combination of the values of the $M$ attributes:

$$
U\left(A_{i}\right)=\sum_{j=1}^{M} w_{j} x_{i j}
$$

where $x_{i j}$ refers to the decision value related to the assessment of the $i$ th alternative against the $j$ th criteria in decision matrix Evaluations and $w_{j}, j=\overline{1, M}$ are weighting coefficients of criteria.

The weighted aggregated sum product assessment (WASPAS) combines SAW and weighted product method by using weighted aggregation formula:

$$
U\left(A_{i}\right)=\lambda \sum_{j=1}^{M} w_{j} x_{i j}+(1-\lambda) \prod_{i=1}^{M} x_{i j}^{w_{j}}, \lambda \in[0,1] .
$$

The multi-attribute border approximation area comparison (MABAC) determines the ranking of alternatives according to their total distance to the border approximation areas of the given criteria. Let $V=\left[v_{i j}\right]_{N \times M}$ be the normalized decision matrix, where $v_{i j}$ refers to the normalized decision value. The border approximation area of each criterion is defined as follows:

$$
g_{j}=\prod_{i=1}^{N} v_{i j}^{1 / N} .
$$

The total distance of each alternative to the border approximation area is given by the next equation:

$$
S_{i}=\sum_{j=1}^{M} q_{i j}
$$

where $q_{i j}=v_{i j}-g_{j}, i=\overline{1, N}$ is the distance to the border approximation area.

The rank the alternatives is based on $S_{i}$ values, ordered in ascending order.

The combinative distance-based assessment (CODAS) algorithm consists of five steps:

1. Determine the negative-ideal solution (point) as given in the next formula:

$$
n s_{j}=\min _{i} v_{i j}
$$

where $v_{i j}$ refers to the normalized decision value related to the assessment of the $i$ th alternative against the $j$ th criteria in normalized decision matrix $V$.

2. Calculate the Euclidean and Manhattan distances of alternatives from the negativeideal solution as given in the next formulas:

$$
E_{i}=\sqrt{\sum_{j=1}^{M}\left(r_{i j}-n s_{j}\right)^{2}}, T_{i}=\sum_{j=1}^{M}\left|r_{i j}-n s_{j}\right| .
$$

3. Construct the relative assessment matrix as follows:

$$
R a=\left[h_{i k}\right]_{N \times N}, h_{i k}=\left(E_{i}-E_{k}\right)+\left(\psi\left(E_{i}-E_{k}\right) \times\left(T_{i}-T_{k}\right)\right),
$$


where $k=\overline{1, N}$ and $\psi$ denotes a threshold function to recognize the equality of the Euclidean distances:

$$
\psi(x)=\left\{\begin{array}{l}
1, \text { if }|x| \geq \tau \\
0, \text { if }|x|<\tau
\end{array} .\right.
$$

In this function, $\tau$ is the threshold parameter that can be set by the decision maker, and it is suggested to set this parameter at a value between 0.01 and 0.05 .

4. Calculate the assessment score of each alternative as follows:

$$
H_{i}=\sum_{k=1}^{n} h_{i k}
$$

5. Rank the alternatives according to the decreasing values of assessment score $\left(H_{i}\right)$. The alternative with the highest $H_{i}$ is the best choice among the alternatives.

The algorithm of measurement of alternatives and ranking according to com-promise solution (MARCOS) consists of six steps.

1. Construction of an extended initial decision matrix. It is assumed that the decision is made in $N$ alternatives and $M$ criteria. In case of group decision-making, the evaluation matrices of the individual experts are aggregated into a collective decision matrix. The extended matrix is a combination of the primary matrix and ideal and anti-ideal solutions as follows:

\begin{tabular}{|c|c|c|c|c}
\hline & $C_{1}$ & $C_{2}$ & $\ldots$ & $C_{M}$ \\
\hline$A A I$ & $x_{A A 1}$ & $x_{A A 2}$ & $\ldots$ & $x_{A A M}$ \\
\cline { 1 - 3 }$A_{1}$ & $x_{11}$ & $x_{12}$ & $\ldots$ & $\ldots$ \\
\hline$A_{N}$ & $\ldots$ & $\ldots$ & $\ldots$ & $x_{1 M}$ \\
\cline { 1 - 3 } & $x_{N 1}$ & $x_{N 2}$ & $\ldots$ & $x_{A M}$ \\
\hline
\end{tabular}

The ideal and anti-ideal solutions are denoted as $A I$ and $A A I$ respectively. The ideal solution is the maximum value among different alternatives with regard to beneficial criteria. In case of a cost criterion, the ideal solution would be the minimum value. For the anti-ideal solution, the process is quite the opposite:

$$
A I=\left\{\begin{array}{c}
\max _{i} x_{i j}, j \in \mathbb{B} ; \\
\min _{i} x_{i j}, j \in \mathbb{C}
\end{array} \text { and } A I=\left\{\begin{array}{c}
\min _{i} x_{i j}, j \in \mathbb{B} ; \\
\max _{i} x_{i j}, j \in \mathbb{C},
\end{array}\right.\right.
$$

where $\mathbb{B}$ denotes the set of maximizing criteria and $\mathbb{C}$ is the group of minimizing criteria.

2. Normalization. The normalized matrix $N=\left[n_{i j}\right]_{N \times M}$ is calculated as:

$$
n_{i j}=\left\{\begin{array}{c}
\frac{x_{i j}}{x_{A i}}, j \in \mathbb{B} ; \\
\frac{x_{A i}}{x_{i j}}, j \in \mathbb{C} .
\end{array}\right.
$$

3. Weighted matrix. The weighted matrix $V=\left[v_{i j}\right]_{N \times M}$ is determined with respect to the criteria weights:

$$
v_{i j}=w_{j} n_{i j}
$$

Weighted values are calculated for the extended matrix.

4. Utility degrees. Utility degrees are given for all the alternatives based on the ideal and anti-ideal solution values by the formulas:

$$
S_{i}=\sum_{i=1}^{n} v_{i j}, K_{i}^{-}=\frac{S_{i}}{S_{A A I}} \text { and } K_{i}^{+}=\frac{S_{i}}{S_{A I}} .
$$


5. Different utility positive and negative functions are calculated. The utility function of each alternative encompasses the utility values and functions:

$$
f\left(K_{i}^{-}\right)=\frac{K_{i}^{+}}{K_{i}^{+}+K_{i}^{-}}, f\left(K_{i}^{+}\right)=\frac{K_{i}^{-}}{K_{i}^{+}+K_{i}^{-}} \text {and } f\left(K_{i}\right)=\frac{K_{i}^{+}+K_{i}^{-}}{1+\frac{1-f\left(K_{i}^{+}\right)}{f\left(K_{i}^{+}\right)}+\frac{1-f\left(K_{i}^{-}\right)}{f\left(K_{i}^{-}\right)}} .
$$

6. Ranking. The alternative ranking relies on the utility function derived from Step 5 of the algorithm.

In case of fuzzy assessments of alternatives, the abovementioned calculations are made according to the rules of fuzzy arithmetic. Let $\widetilde{a}=\left(a_{1}, a_{2}, a_{3}\right)$ and $\widetilde{b}=\left(b_{1}, b_{2}, b_{3}\right)$ be two fuzzy triangular numbers. The arithmetic operations with these fuzzy numbers are defined as follows:

$$
\begin{aligned}
& \text { Addition: } \widetilde{a}+\widetilde{b}=\left(a_{1}+b_{1}, a_{2}+b_{2}, a_{3}+b_{3}\right) \\
& \text { Subtraction: } \widetilde{a}-\widetilde{b}=\left(a_{1}-b_{3}, a_{2}-b_{2}, a_{3}-b_{1}\right)
\end{aligned}
$$

Multiplication: $\widetilde{a} \times \widetilde{b}=\left(\min \left(a_{1} b_{1}, a_{1} b_{3}, a_{3} b_{1}, a_{3} b_{3}\right), a_{2} b_{2}, \max \left(a_{1} b_{1}, a_{1} b_{3}, a_{3} b_{1}, a_{3} b_{3}\right)\right)$

$$
\text { Division : } \widetilde{a} / \widetilde{b}=\left(\begin{array}{c}
\min \left(a_{1} / b_{1}, a_{1} / b_{3}, a_{3} / b_{1}, a_{3} / b_{3}\right), \\
a_{2} b_{2}, \max \left(a_{1} / b_{1}, a_{1} / b_{3}, a_{3} / b_{1}, a_{3} / b_{3}\right)
\end{array}\right)
$$

Defuzzification rule: Let graded mean integration representation (GMIR) of a fuzzy triangular number $\widetilde{a}$ be $G(\widetilde{a})$. Let $\widetilde{a}_{i}=\left(l_{i}, m_{i}, u_{i}\right)$, then the defuzzification rule is:

$$
G\left(\widetilde{a}_{i}\right)=\frac{l_{i}+4 m_{i}+u_{i}}{6}
$$

In the next section, we apply the new methodology to solve a practical problem for blockchain software evaluation via MARCOS method.

\section{Numerical Example}

In intelligent agriculture, farmers, processors and distributors often have to negotiate and sign contracts for production and supply of agricultural products with clauses stipulated in advance. Blockchain-based software for smart contracts automate the execution of agreements so that all participants can be immediately certain of the outcome, without time loss. Contract management software not only reliably stores multiple contracts, but also automatically executes them without intermediaries. This software is especially useful for agricultural companies because the surrounding environment is dynamic, the changes in supply chain are rapid, and a quick response is required.

Let $A F$ be a randomly selected firm exposed to a smart contract selection problem. The benefits of blockchain for smart contracts over traditional software are numerous. The problem is how to find what is the best blockchain-based smart contracts system for the particular firm.

In this illustrative example, we utilize a blockchain software dataset, collected from Capterra.com. The dataset consists of six blockchain-based smart contracts products $\left(A_{1}, A_{2}\right.$, $\left.\ldots, A_{6}\right)$. The blockchain-based smart contracts applications are as follows: $A_{1}-$ Comforce, $A_{2}$ - Concord, $A_{3}$-ContractPodAi, $A_{4}$-GateKeeper, $A_{5}$-Icertis Suite, and $A_{6}$-Symfact. The assessment dimensions include five criteria groups $\left(C_{1}, C_{2}, \ldots, C_{5}\right)$. These criteria groups are related to the different aspects of smart contracts management software: $C_{1}$ functionality, $C_{2}$-deployment, $C_{3}$ - support, $C_{4}$-training, and $C_{5}$-customer ratings. Each criteria group represents a set of product features.

Step 1. Let the execution of Step 1 of the proposed framework show that the firm's $A F$ suitability index is true.

Step 2. A team of experts from firm $A F$ fill in the questionnaire about their smart contracts' requirements (Appendix A). Respondents evaluate the blockchain features using 
five-point Likert scale from "extremely important" (corresponding to 5) to "unimportant" (corresponding to 1 ).

Step 3. In this step, an evaluation index $C$ is constructed, $C=\left[C_{j}\right], j=\overline{1,5}$. The assessments of alternatives by criteria are equal to the number of available features in the respective category (Appendix B).

Step 4. The decision matrix values are converted into linguistic variables from sevenpoint scale (Table 2). For transformation of every linguistic variable into its corresponding symmetric triangular fuzzy number (TFN), the correspondence table (Table 3) is applied.

Table 2. Decision matrix for blockchain-based smart contracts software.

\begin{tabular}{lccccc}
\hline & $C_{1}$ & $C_{2}$ & $C_{3}$ & $C_{4}$ & $C_{5}$ \\
\hline$A_{1}$ & $\mathrm{H}$ & $\mathrm{L}$ & $\mathrm{ML}$ & $\mathrm{MH}$ & $\mathrm{VH}$ \\
$A_{2}$ & $\mathrm{VH}$ & $\mathrm{ML}$ & $\mathrm{H}$ & $\mathrm{VH}$ & $\mathrm{ML}$ \\
$A_{3}$ & $\mathrm{VH}$ & $\mathrm{L}$ & $\mathrm{H}$ & $\mathrm{VH}$ & $\mathrm{M}$ \\
$A_{4}$ & $\mathrm{VH}$ & $\mathrm{ML}$ & $\mathrm{VH}$ & $\mathrm{VH}$ & $\mathrm{MH}$ \\
$A_{5}$ & $\mathrm{VH}$ & $\mathrm{ML}$ & $\mathrm{MH}$ & $\mathrm{VH}$ & $\mathrm{L}$ \\
$A_{6}$ & $\mathrm{VH}$ & $\mathrm{M}$ & $\mathrm{M}$ & $\mathrm{H}$ & $\mathrm{VL}$ \\
\hline
\end{tabular}

Table 3. Linguistic variables and their corresponding triangular fuzzy numbers.

\begin{tabular}{ll}
\hline \multicolumn{1}{c}{ Linguistic Term } & \multicolumn{1}{c}{ Symmetric TFN } \\
\hline Very low (VL) & $(0,0,0.17)$ \\
Low (L) & $(0,0.17,0.33)$ \\
Medium Low (ML) & $(0.17,0.33,0.5)$ \\
Medium (M) & $(0.33,0.5,0.67)$ \\
Medium High (MH) & $(0.5,0.67,0.83)$ \\
High (H) & $(0.67,0.83,1)$ \\
Very High (VH) & $(0.83,1,1)$ \\
\hline
\end{tabular}

The importance of each category from the questionnaire about user requirements is multiplied by average value of the features from the same category (Appendix $C$ ). The final weights $W_{j}, j=\overline{1,5}$ are normalized such that:

$$
\sum_{j=1}^{5} W_{j}=1
$$

The obtained weighting coefficients are as follows: $W_{1}=W_{2}=W_{3}=W_{4}=0.1$ and $W_{5}$ $=0.6($ Set-1) $($ Appendix C).

In order to test the sensitivity of the MCDM method we repeat the calculations with a second weighting coefficients set: $W_{1}=W_{2}=W_{3}=W_{4}=W_{5}=0.2$ (Set-2) (Step 4).

The two sets represent different combinations of criteria importance: Set-1 emphasizes on respondent's opinion about customer ratings $\left(C_{5}\right)$, while Set-2 demonstrates the equal importance of evaluation criteria. The next step is the multi-criteria analysis.

Step 5. The obtained scores and rankings of given contract management software by using crisp and fuzzy MARCOS method for the two sets of weighting coefficients are displayed in Tables 4 and 5, respectively (Step 5). 
Table 4. Overall alternative scores and their corresponding ranking-MARCOS method, crisp values.

\begin{tabular}{ccccc}
\hline & \multicolumn{2}{c}{ Set-1 } & \multicolumn{2}{c}{ Set-2 } \\
\hline & Score & Rank & Score & Rank \\
\hline$A_{\mathbf{1}}$ & 0.784 & 1 & 0.592 & 6 \\
$\boldsymbol{A}_{\mathbf{2}}$ & 0.570 & 4 & 0.682 & 2 \\
$\boldsymbol{A}_{\mathbf{3}}$ & 0.626 & 3 & 0.664 & 3 \\
$\boldsymbol{A}_{\mathbf{4}}$ & 0.741 & 2 & 0.755 & 1 \\
$\boldsymbol{A}_{\mathbf{5}}$ & 0.478 & 5 & 0.634 & 4 \\
$\boldsymbol{A}_{\mathbf{6}}$ & 0.395 & 6 & 0.604 & 5 \\
\hline
\end{tabular}

Table 5. Overall alternative scores and their corresponding ranking-MARCOS method, TFNs.

\begin{tabular}{ccccc}
\hline & \multicolumn{2}{c}{ Set-1 } & \multicolumn{2}{c}{ Set-2 } \\
\hline & Score & Rank & Score & Rank \\
\hline $\boldsymbol{A}_{\mathbf{1}}$ & 0.785 & 1 & 0.452 & 6 \\
$\boldsymbol{A}_{\mathbf{2}}$ & 0.536 & 4 & 0.662 & 2 \\
$\boldsymbol{A}_{\mathbf{3}}$ & 0.605 & 3 & 0.601 & 3 \\
$\boldsymbol{A}_{\mathbf{4}}$ & 0.753 & 2 & 0.773 & 1 \\
$\boldsymbol{A}_{\mathbf{5}}$ & 0.427 & 5 & 0.585 & 5 \\
$\boldsymbol{A}_{\mathbf{6}}$ & 0.327 & 6 & 0.601 & 4 \\
\hline
\end{tabular}

The obtained crisp and fuzzy MARCOS rankings by weights' sets are similar. The final fuzzy MARCOS ranking is as follows:

Set-1: $\mathrm{A}_{1} \succ \mathrm{A}_{4} \succ \mathrm{A}_{3} \succ \mathrm{A}_{2} \succ \mathrm{A}_{5} \succ \mathrm{A}_{6}$;

Set-2: $A_{4} \succ A_{2} \succ A_{3} \succ A_{6} \succ A_{5} \succ A_{1}$.

Step 6 . In order to check the consistency of the results produced by crisp and fuzzy assessments and the robustness of the models, a sensitivity analysis is performed. Spearman's rank correlation coefficient and percentage of identical rankings are applied as a similarity measures between fuzzy and crisp solutions for each set of weighted coefficients. In the two cases, Spearman's coefficients and percentages of identical rankings indicate high degrees of closeness-1.000 (Set-1) and 0.943 (Set-2), 100\% (Set-1) and 83\% (Set-2). This means that both crisp and fuzzy models are very robust. Spearman's coefficient and percentage of identical rankings of models by sets of weights are 0.086 and $16.67 \%$ for the crisp model, and 0.029 and $33.33 \%$ for the fuzzy model. The obtained results demonstrate high degrees of sensitivity to changes in weighting coefficients.

According to the obtained results, the both MARCOS models are robust and stable to changes in assessments (crisp and fuzzy), while the fuzzy model is more affected by changes in weighting coefficients (Set-1 and Set-2).

The analysis also shows that two groups of smart contracts software can be distinguished in the obtained fuzzy MARCOS rankings:

Set-1:

Group 1. Smart contracts software with highest assessments- $A_{1}, A_{4}$, and $A_{3}$;

Group 2. Smart contracts software with relative low assessments- $A_{2}, A_{5}$, and $A_{6}$

by criterion $C_{5}$ (customer ratings) as maximum important feature.

Set-2:

Group 1. Smart contracts software with highest assessments- $A_{4}, A_{2}$, and $A_{3}$;

Group 2. Smart contracts software with relative low assessments- $A_{6}, A_{5}$, and $A_{1}$,

when all criteria weights are equal.

The highest customer ratings of alternative $A_{1}$ (Comforce) assign it to the leading group in the first ranking (Set-1), while alternative $A_{6}$ (Symfact) falls into the second part of the ranking. According to the obtained second ranking (Set-2), the leader is alternative $A_{4}$ (GateKeeper). The first place of $A_{4}$ corresponds with Capterra assertion, that GateKeeper is "emerging favorite" among contract management software. Therefore, it can be concluded, 
that the proposed framework is reliable and properly reflects the requirements and needs of firm $A F$.

The new multi-criteria framework provides reliable solution to the blockchain product selection problem using users' preferences and experts' opinions. The unification of the procedure of choosing the best blockchain alternative eliminates subjectivism and suppresses differences in respondents' expertise. The framework is flexible and time-saving and it reduces the possibility of errors while providing accurate information for each stage of the decision-making process. Furthermore, it facilitates the construction of complex criteria (indices) for blockchain software evaluation, including new ISO blockchain standard, critical success factors or other metrics for software quality. Unlike previous similar studies, the new framework implements several multi-criteria methods in a fuzzy environment. The proposed framework improves the decision-making process and increases the efficiency of blockchain software selection.

\section{Conclusions}

The rapid growth of data and increased requirements for its security and traceability reinforce the need for implementing blockchain systems in organizations. With its capabilities for reliable data storage, guaranteed access for authorized users and inability to alter and compromise transactional data, blockchain is an important tool for achieving organizational efficiency and effectiveness.

Agriculture is a promising area for implementation of blockchain technology. Trade in agricultural products depends on complex relationships between farmers and retailers, and food supply chains are often blocked due to late payments and substandard goods. Digitization of agriculture with blockchain-based system ensures transactions' monitoring and improves control, while eliminating delays in the supply chain and increasing the quality of food products offered.

The results of our study show that there are some problems in blockchain implementations: (1) blockchain requires significant resources (financial, technological, human and material); (2) specific laws and regulations restrict access to distributed computing infrastructure; (3) blockchain poses some potential risks (e.g., fraud, price manipulation, misuse of personal data). Most of these problems can be avoided by increasing the awareness of the principles and features of blockchain technology.

The process of determining the best suitable blockchain software in organizations depends on many factors, for example, peculiarities of work processes and surrounding ecosystem. It is, in fact, a multi-criteria decision making problem. In this study, we propose a unified conceptual framework for evaluation of blockchain alternatives comprising of a variety of decision analysis methods with crisp and fuzzy assessments. The new framework automates prioritizing blockchain software and has many advantages:

(1) Group approach in decision making takes into account a larger data volume since each user and team member is able to contribute according to their particular expertise;

(2) Relying on a number of decision-making methods ranging from traditional, utility based to contemporary, similarity based, with relatively low time complexity, ensures solution for various input data;

(3) Capability to handle vague and uncertain estimates of both cost and beneficial criteria;

(4) Applicability even in case of small list of compared objects, while the alternative probabilistic approach is suitable only for a large number of homogeneous observations.

The distinguished characteristic of the new fuzzy methodology is that the weighting coefficients and decision matrices are determined by users and a team of experts according to organization's specifics. The proposed evaluation system is flexible and can be expanded easily.

The validity of the new framework is proven by a practical example for selection of blockchain-based contract management software. The task is to find the best ranking alternative from six software products (Comforce, Concord, ContractPodAi, GateKeeper, Icertis Suite and Symfact). Five dimensions were proposed for blockchain software comparison- 
functionality, deployment, support, training and customer ratings. Each of these indices depends on several criteria and the total number of criteria, identified by stakeholders, is thirty-two. The analysis of obtained results shows that the proposed methodology is suitable, reliable and correctly reflects user's requirements.

The limitations of our study are as follows: (1) the task of finding the most appropriate blockchain software is solved only by soft computing methods; (2) the choice of appropriate alternatives and criteria for their ranking requires experts' knowledge; (3) the selection of decision-making method depends on the problem specifics, and it is not a trivial task.

In the future, we plan to develop new hybrid methods for blockchain software evaluation combining weights determination algorithms with multi-criteria decision-making methods. Additionally, the proposed mechanism for ranking of blockchain alternatives will be expanded to address uncertainty of estimates with advanced variants of classical type-1 fuzzy numbers.

Author Contributions: Conceptualization, G.I. and T.Y.; methodology, G.I.; software, G.I.; validation, T.Y.; formal analysis, T.Y.; investigation, I.R.; data curation, T.Y.; writing-original draft preparation, G.I. and T.Y.; writing - review and editing, G.I.; visualization, T.Y.; supervision, I.P.; project administration, I.R.; funding acquisition, I.R. All authors have read and agreed to the published version of the manuscript.

Funding: This research was partially funded by the National Research Programme "Smart Crop Production", approved by decision of the Ministry Council No. 866/26.11.2020, by the Ministry of Education and Science, Grant No. KP-06-PN36/2 BG PLANTNET "Establishment of National Information Network GENEBANK-Plant Genetic Resources" and by a Grant No. BG05M2OP0011.002-0002-C02 "Digitization of the Economy in Big Data Environment" of the National Science Fund, co-founded by the European Regional Development Fund.

Institutional Review Board Statement: Not applicable.

Informed Consent Statement: Not applicable.

Data Availability Statement: Not applicable.

Acknowledgments: The authors thank the academic editor and anonymous reviewers for their insightful comments and suggestions.

Conflicts of Interest: The authors declare no conflict of interest.

\section{Appendix A. Business Requirements for Blockchain Software and Smart Contracts Questionnaire}

Please respond to the following questions by filling in the blanks where indicated and/or placing a check mark $(\sqrt{ })$ in the answer box that corresponds to your response (one response per row).

1. Company name:

2. Location:

Blockchain software categories

3. How important is each blockchain software category for your business?

\begin{tabular}{|c|c|c|c|c|c|}
\hline & Extremely Important & Very Important & Important & Less Important & Unimportant \\
\hline \multicolumn{6}{|l|}{ Functionality } \\
\hline \multicolumn{6}{|l|}{ Deployment } \\
\hline \multicolumn{6}{|l|}{ Support } \\
\hline \multicolumn{6}{|l|}{ Training } \\
\hline Customer Ratings & & & & & \\
\hline
\end{tabular}




\section{Functionality category}

4. How important is each functionality feature for your business?

\begin{tabular}{|c|c|c|c|c|c|}
\hline & Extremely Important & Very Important & Important & Less Important & Unimportant \\
\hline \multicolumn{6}{|l|}{ Buy Side (Suppliers) } \\
\hline \multicolumn{6}{|l|}{ Completion Tracking } \\
\hline \multicolumn{6}{|l|}{ Compliance Tracking } \\
\hline \multicolumn{6}{|l|}{$\begin{array}{l}\text { Contract Lifecycle } \\
\text { Management }\end{array}$} \\
\hline \multicolumn{6}{|l|}{ Electronic Signature } \\
\hline \multicolumn{6}{|l|}{ Full Text Search } \\
\hline \multicolumn{6}{|l|}{ Government Contracts } \\
\hline \multicolumn{6}{|l|}{ Pre-Built Templates } \\
\hline \multicolumn{6}{|l|}{ Sell Side (Customers) } \\
\hline \multicolumn{6}{|l|}{ Specialty Contracts } \\
\hline \multicolumn{6}{|l|}{ Version Control } \\
\hline Workflow Management & & & & & \\
\hline
\end{tabular}

Deployment category

5. How important is each deployment feature for your business?

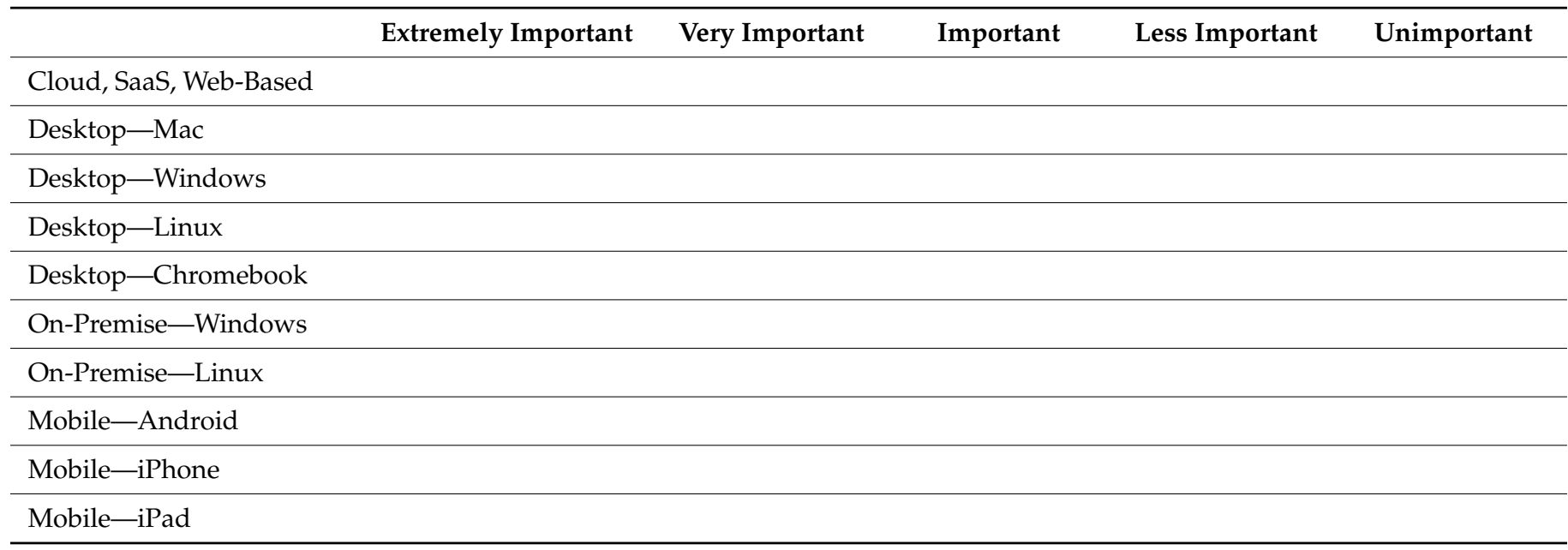

\section{Support category}

6. How important is each support feature for your business?

\begin{tabular}{|c|c|c|c|c|c|}
\hline & Extremely Important & Very Important & Important & Less Important & Unimportant \\
\hline \multicolumn{6}{|l|}{ Email/Help Desk } \\
\hline \multicolumn{6}{|l|}{ FAQs/Forum } \\
\hline \multicolumn{6}{|l|}{ Knowledge Base } \\
\hline \multicolumn{6}{|l|}{ Phone Support } \\
\hline \multicolumn{6}{|l|}{ 24/7 (Live Rep) } \\
\hline Chat & & & & & \\
\hline
\end{tabular}


Training category

7. How important is each training feature for your business?

\begin{tabular}{lllll}
\hline & Extremely Important & Very Important & Important & Less Important \\
\hline In Person & & & Unimportant \\
\hline Live Online & & \\
\hline Webinars & & \\
\hline Documentation & \\
\hline Videos
\end{tabular}

Customer ratings category

8. How important is each customer ratings feature for your business?

\begin{tabular}{|c|c|c|c|c|c|}
\hline & Extremely Important & Very Important & Important & Less Important & Unimportant \\
\hline \multicolumn{6}{|l|}{ Ease of Use } \\
\hline \multicolumn{6}{|l|}{ Customer Service } \\
\hline \multicolumn{6}{|l|}{ Features } \\
\hline \multicolumn{6}{|l|}{ Value for Money } \\
\hline \multicolumn{6}{|l|}{ Overall } \\
\hline $\begin{array}{l}\text { Likelihood to } \\
\text { Recom-mend (\%) }\end{array}$ & & & & & \\
\hline
\end{tabular}

\section{Cost of blockchain software}

9. How important is cost of blockchain software for your business?

\begin{tabular}{llllll}
\hline & Extremely Important & Very Important & Important & Less Important Unimportant \\
\hline Low cost & & &
\end{tabular}

Source: Based on https: / /www.capterra.com/contract-management-software/, accessed on 21 September 2021.

Appendix B. Blockchain Applications for Smart Contracts and Its Attributes

\begin{tabular}{lcccccc}
\hline & Comforce & Concord & ContractPodAi & GateKeeper & Icertis Suite & Symfact \\
\hline Functionality & & & 1 & 1 & 1 & 1 \\
\hline Buy Side (Suppliers) & 1 & 1 & 1 & 1 & 1 & 1 \\
\hline Completion Tracking & 1 & 1 & 1 & 1 & 1 \\
\hline Compliance Tracking & 1 & 1 & 1 & 1 & 1 \\
\hline Contract Lifecycle & 1 & 1 & 1 & 1 & 1 \\
Management & 1 & 1 & 1 & 1 & 1 \\
\hline Electronic Signature & 1 & 1 & 1 & 1 & 1 \\
\hline Full Text Search & 1 & 1 & 1 & 1 & 1 \\
\hline Government Contracts & 1 & 1 & 1 & 1 & 1 \\
\hline Pre-Built Templates & 1 & 1 & 1 & 1 & 1 \\
\hline Sell Side (Customers) & 1 & 1 & 1 & 1 & 1 \\
\hline Specialty Contracts & 11 & 12 & 1 & 1 & 1 \\
\hline Version Control & 1 & 1 & 1 & 1 \\
\hline Workflow Management & Count: & 1 & 1 & 1 \\
\hline
\end{tabular}




\begin{tabular}{|c|c|c|c|c|c|c|}
\hline & Comforce & Concord & ContractPodAi & GateKeeper & Icertis Suite & Symfact \\
\hline \multicolumn{7}{|l|}{ Deployment } \\
\hline Cloud, SaaS, Web-Based & 1 & 1 & 1 & 1 & 1 & 1 \\
\hline Desktop-Mac & & & & & & 1 \\
\hline Desktop—Windows & & & & & 1 & 1 \\
\hline \multicolumn{7}{|l|}{ Desktop-Linux } \\
\hline \multicolumn{7}{|l|}{ Desktop—Chromebook } \\
\hline On-Premise-Windows & & & & & 1 & 1 \\
\hline On-Premise-Linux & & & & & 1 & 1 \\
\hline Mobile-Android & & 1 & & 1 & & \\
\hline Mobile-iPhone & & 1 & & 1 & & \\
\hline Mobile-iPad & & 1 & & 1 & & \\
\hline Count: & 1 & 4 & 1 & 4 & 4 & 5 \\
\hline \multicolumn{7}{|l|}{ Support } \\
\hline Email/Help Desk & & 1 & 1 & 1 & 1 & 1 \\
\hline FAQs/Forum & & 1 & & 1 & & \\
\hline Knowledge Base & & 1 & 1 & 1 & 1 & \\
\hline Phone Support & & 1 & 1 & 1 & 1 & 1 \\
\hline 24/7 (Live Rep) & 1 & & 1 & 1 & & \\
\hline Chat & 1 & 1 & 1 & 1 & 1 & 1 \\
\hline Count: & 2 & 5 & 5 & 6 & 4 & 3 \\
\hline \multicolumn{7}{|l|}{ Training } \\
\hline In Person & 1 & 1 & 1 & 1 & 1 & 1 \\
\hline Live Online & 1 & 1 & 1 & 1 & 1 & 1 \\
\hline Webinars & & 1 & 1 & 1 & 1 & 1 \\
\hline Documentation & 1 & 1 & 1 & 1 & 1 & 1 \\
\hline Videos & & 1 & 1 & 1 & 1 & \\
\hline Count: & 3 & 5 & 5 & 5 & 5 & 4 \\
\hline \multicolumn{7}{|l|}{ Customer Ratings } \\
\hline Ease of Use & 1.0 & 0.3 & 0.4 & 0.7 & 0.2 & 0.0 \\
\hline Customer Service & 1.0 & 0.5 & 0.6 & 0.8 & 0.0 & 0.3 \\
\hline Features & 1.0 & 0.2 & 0.5 & 0.6 & 0.2 & 0.0 \\
\hline Value for Money & 1.0 & 0.6 & 0.4 & 0.7 & 0.1 & 0.0 \\
\hline $\begin{array}{l}\text { Likelihood to } \\
\text { Recommend }\end{array}$ & 1.0 & 0.3 & 0.3 & 0.7 & 0.1 & 0.0 \\
\hline Overall & 1.0 & 0.3 & 0.5 & 0.8 & 0.1 & 0.0 \\
\hline Sum: & 6.0 & 2.2 & 2.8 & 4.2 & 0.8 & 0.3 \\
\hline
\end{tabular}


Appendix C. Business Requirements for Blockchain Based Contract Management

Customer: $A F$

Location: $X$

\begin{tabular}{|c|c|c|c|c|c|c|}
\hline $\begin{array}{l}\text { Blockchain Software } \\
\text { Categories }\end{array}$ & $\begin{array}{l}\text { Extremely } \\
\text { Important }\end{array}$ & $\begin{array}{l}\text { Very } \\
\text { Important }\end{array}$ & Important & $\begin{array}{l}\text { Less } \\
\text { Important }\end{array}$ & Unimportant & \\
\hline Functionality & & & 3 & & & \\
\hline Deployment & & & 3 & & & \\
\hline Support & & & 3 & & & \\
\hline Training & & & & 2 & & \\
\hline Customer Ratings & 5 & & & & & \\
\hline Functionality Category & $\begin{array}{l}\text { Extremely } \\
\text { Important }\end{array}$ & $\begin{array}{l}\text { Very } \\
\text { Important }\end{array}$ & Important & $\begin{array}{l}\text { Less } \\
\text { Important }\end{array}$ & Unimportant & \\
\hline Buy Side (Suppliers) & & & & 2 & & \\
\hline Completion Tracking & & & & 2 & & \\
\hline Compliance Tracking & & & & & 1 & \\
\hline $\begin{array}{l}\text { Contract Lifecycle } \\
\text { Management }\end{array}$ & & & 3 & & & \\
\hline Electronic Signature & & & 3 & & & \\
\hline Full Text Search & & & & 2 & & \\
\hline Government Contracts & & & & & 1 & \\
\hline Pre-Built Templates & & & & 2 & & \\
\hline Sell Side (Customers) & & & & 2 & & \\
\hline Specialty Contracts & & & & & 1 & \\
\hline Version Control & & & & & $\begin{array}{l}\text { Total } \\
\text { sum: }\end{array}$ & Count: \\
\hline $\begin{array}{l}\text { Workflow } \\
\text { Management }\end{array}$ & & & & & 21 & 12 \\
\hline Deployment Category & $\begin{array}{l}\text { Extremely } \\
\text { Important }\end{array}$ & $\begin{array}{l}\text { Very } \\
\text { Important }\end{array}$ & Important & $\begin{array}{l}\text { Less } \\
\text { Important }\end{array}$ & Unimportant & \\
\hline Cloud, SaaS, Web-Based & & 4 & & & & \\
\hline Desktop-Mac & & & & 2 & & \\
\hline Desktop—Windows & & & & 2 & & \\
\hline Desktop-Linux & & & & 2 & & \\
\hline Desktop-Chromebook & & & & 2 & & \\
\hline On-Premise-Windows & & & 3 & & & \\
\hline
\end{tabular}




\begin{tabular}{|c|c|c|c|c|c|c|c|}
\hline On-Premise-Linux & & & 3 & & & & \\
\hline Mobile-Android & & & & & & & \\
\hline Mobile_-iPhone & & & & 2 & & $\begin{array}{l}\text { Total } \\
\text { sum: }\end{array}$ & Count: \\
\hline Mobile_-iPad & & & & 2 & & 22 & 9 \\
\hline Support Category & $\begin{array}{l}\text { Extremely } \\
\text { Important }\end{array}$ & $\begin{array}{l}\text { Very } \\
\text { Important }\end{array}$ & Important & $\begin{array}{l}\text { Less } \\
\text { Important }\end{array}$ & Unir & $\operatorname{tant}$ & \\
\hline Email/Help Desk & & 4 & & & & & \\
\hline FAQs/Forum & & & 3 & & & & \\
\hline Knowledge Base & & & & 2 & & & \\
\hline Phone Support & & & & 2 & & & \\
\hline 24/7 (Live Rep) & & & & & 1 & $\begin{array}{l}\text { Total } \\
\text { sum: }\end{array}$ & Count: \\
\hline Chat & & & & 2 & & 14 & 6 \\
\hline Training & $\begin{array}{l}\text { Extremely } \\
\text { Important }\end{array}$ & $\begin{array}{l}\text { Very } \\
\text { Important }\end{array}$ & Important & $\begin{array}{l}\text { Less } \\
\text { Important }\end{array}$ & Unir & $\operatorname{tant}$ & \\
\hline In Person & & & & 2 & & & \\
\hline Live Online & & & & 2 & & & \\
\hline Webinars & & & 3 & & & & \\
\hline Documentation & & & 3 & & & $\begin{array}{l}\text { Total } \\
\text { sum: }\end{array}$ & Count: \\
\hline Videos & & & 3 & & & 13 & 5 \\
\hline Customer Ratings & $\begin{array}{l}\text { Extremely } \\
\text { Important }\end{array}$ & $\begin{array}{l}\text { Very } \\
\text { Important }\end{array}$ & Important & $\begin{array}{l}\text { Less } \\
\text { Important }\end{array}$ & Unin & tant & \\
\hline Ease of Use & 5 & & & & & & \\
\hline Customer Service & 5 & & & & & & \\
\hline Features & 5 & & & & & & \\
\hline Value for Money & 5 & & & & & & \\
\hline Likelihood to Recommend & 5 & & & & & $\begin{array}{l}\text { Total } \\
\text { sum: }\end{array}$ & Count: \\
\hline Overall & 5 & & & & & 30 & 6 \\
\hline $\begin{array}{l}\text { Blockchain Software } \\
\text { Categories }\end{array}$ & Functionality & Deployment & Support & Training & $\begin{array}{l}\text { Cust } \\
\text { Ratis }\end{array}$ & & \\
\hline Extremely Important & 0 & 0 & 0 & 0 & 5 & & \\
\hline Very Important & 0 & 0 & 0 & 0 & 0 & & \\
\hline Important & 3 & 0 & 0 & 0 & 0 & & \\
\hline Less Important & 0 & 2 & 2 & 2 & 0 & & \\
\hline Unimportant & 0 & 0 & 0 & 0 & 0 & & \\
\hline $\begin{array}{l}\text { Average value } \\
\text { per category: }\end{array}$ & 1.8 & 2.4 & 2.3 & 2.6 & 5.0 & $\begin{array}{l}\text { Total } \\
\text { sum: }\end{array}$ & \\
\hline $\begin{array}{l}\text { Weighted average } \\
\text { value per category: }\end{array}$ & 5.3 & 4.9 & 4.7 & 5.2 & 25.0 & 45.0 & \\
\hline $\begin{array}{l}\text { Relative } \\
\text { category weight: }\end{array}$ & 0.1 & 0.1 & 0.1 & 0.1 & 0.6 & 1.0 & \\
\hline
\end{tabular}




\section{References}

1. Amir, A. Evolution of the Agriculture Industry and Its Role in Agricultural Innovation. Available online: https://www. emeraldgrouppublishing.com/opinion-and-blog/evolution-agriculture-industry-its-role-agricultural-innovation (accessed on 17 August 2021).

2. Valle, S.S.; Kienzle, J. Agriculture 4.0-Agricultural robotics and automated equipment for sustainable crop production. Integr. Crop Manag. 2020, 24, 40.

3. Boursianis, A.D.; Papadopoulou, M.S.; Diamantoulakis, P.; Liopa-Tsakalidi, A.; Barouchas, P.; Salahas, G.; Karagiannidis, G.; Wan, S.; Goudos, S.K. Internet of Things (IoT) and Agricultural Unmanned Aerial Vehicles (UAVs) in smart farming: A comprehensive review. Internet Things 2020, 100187, in press. [CrossRef]

4. Demestichas, K.; Peppes, N.; Alexakis, T.; Adamopoulou, E. Blockchain in Agriculture Traceability Systems: A Review. Appl. Sci. 2020, 10, 4113. [CrossRef]

5. Kamilaris, A.; Fonts, A.; Prenafeta-Bold v́, F.X. The rise of blockchain technology in agriculture and food supply chains. Trends Food Sci. Technol. 2019, 91, 640-652. [CrossRef]

6. Mirabelli, G.; Solina, V. Blockchain and agricultural supply chains traceability: Research trends and future challenges. Procedia Manuf. 2020, 42, 414-421. [CrossRef]

7. Xiong, H.; Dalhaus, T.; Wang, P.; Huang, J. Blockchain Technology for Agriculture: Applications and Rationale. Front. Blockchain 2020, 3, 7. [CrossRef]

8. Feng, H.; Wang, X.; Duan, Y.; Zhang, J.; Zhang, X. Applying blockchain technology to improve agri-food traceability: A review of development methods, benefits and challenges. J. Clean. Prod. 2020, 260, 121031. [CrossRef]

9. Scriber, B.A. A framework for determining blockchain applicability. IEEE Softw. 2018, 35, 70-77. [CrossRef]

10. Nayak, G.; Dhaigude, A.S. A conceptual model of sustainable supply chain management in small and medium enterprises using blockchain technology. Cogent Econ. Financ. 2019, 7, 1667184. [CrossRef]

11. Clohessy, T.; Acton, T.; Rogers, N. Blockchain adoption: Technological, organisational and environmental considerations. In Business Transformation through Blockchain; Treiblmaier, H., Beck, R., Eds.; Palgrave Macmillan: Cham, Switzerland, 2019; Volume I, pp. $47-76$.

12. Colomo-Palacios, R.; Sánchez-Gordón, M.; Arias-Aranda, D. A critical review on blockchain assessment initiatives: A technology evolution viewpoint. J. Softw. Evol. Process 2020, 32, 11. [CrossRef]

13. Maček, D.; Alagić, D. Comparisons of bitcoin cryptosystem with other common Internet transaction systems by AHP technique. J. Inf. Org. Sci. 2017, 41, 69-87. [CrossRef]

14. Büyüközkan, G.; Tüfekçi, G. A decision-making framework for evaluating appropriate business blockchain platforms using multiple preference formats and VIKOR. Inf. Sci. 2021, 571, 337-357. [CrossRef]

15. Nanayakkara, S.; Rodrigo, M.N.N.; Perera, S.; Weerasuriya, G.T.; Hijazi, A.A. A methodology for selection of a Blockchain platform to develop an enterprise system. J. Ind. Inf. Integr. 2021, 23, 100215.

16. Ar, I.M.; Erol, I.; Peker, I.; Ozdemir, A.; Medeni, T.; Medeni, I.T. Evaluating the feasibility of blockchain in logistics operations: A decision framework. Expert Syst. Appl. 2020, 158, 113543. [CrossRef]

17. Tang, H.; Shi, Y.; Dong, P. Public blockchain evaluation using entropy and TOPSIS. Expert Syst. Appl. 2019, 117, 204-210. [CrossRef]

18. Lai, H.; Liao, H. A multi-criteria decision making method based on DNMA and CRITIC with linguistic D numbers for blockchain platform evaluation. Eng. Appl. Artif. Intell. 2021, 101, 104200. [CrossRef]

19. Ilieva, G. Decision analysis for big data platform selection. Eng. Sci. 2019, LVI, 5-18. [CrossRef]

20. Popchev, I. Soft Computing: Three Decades Fuzzy Models and Applications. In Research in Computer Science in the Bulgarian Academy of Sciences. Studies in Computational Intelligence; Atanassov, K.T., Ed.; Springer: Berlin/Heidelberg, Germany, 2021; Volume 934, pp. 55-100.

21. Pamučar, D.; Ćirović, G. The selection of transport and handling resources in logistics centers using Multi-Attribute Border Approximation area Comparison (MABAC). Expert Syst. Appl. 2015, 42, 3016-3028. [CrossRef]

22. Keshavarz Ghorabaee, M.; Zavadskas, E.K.; Turskis, Z.; Antucheviciene, J. A new Combinative Distance-based Assessment (CODAS) method for multi-criteria decision-making. Econ. Comput. Econ. Cybern. Stud. Res. 2016, 50, $25-44$.

23. Stević, Ž.; Pamučar, D.; Puška, A.; Chatterjee, P. Sustainable supplier selection in healthcare industries using a new MCDM method: Measurement of alternatives and ranking according to compromise solution (MARCOS). Comput. Ind. Eng. 2020, 140, 106231. [CrossRef]

24. Chakraborty, S.; Zavadskas, E.K. Applications of WASPAS method in manufacturing decision making. Informatica 2014, 25, 1-20. [CrossRef]

25. Crosby, M.; Nachiappan, P.P.; Verma, S.; Kalyanaraman, V. BlockChain Technology; Sutardja Center for Entreneurship \& Technology, University of California: Berkeley, NY, USA, 2015; p. 35.

26. Lezoche, M.; Hernandez, J.E.; Díaz, M.M.E.A.; Panetto, H.; Kacprzyk, J. Agri-food 4.0: A survey of the supply chains and technologies for the future agriculture. Comput. Ind. 2020, 117, 103187. [CrossRef]

27. Saberi, S.; Kouhizadeh, M.; Sarkis, J.; Shen, L. Blockchain technology and its relationships to sustainable supply chain management. Int. J. Prod. Res. 2019, 57, 2117-2135. [CrossRef] 
28. Zhu, Q.; Kouhizadeh, M. Blockchain Technology, Supply Chain Information, and Strategic Product Deletion Management. IEEE Eng. Manag. Rev. 2019, 47, 36-44. [CrossRef]

29. Fernandez-Vazquez, S.; Rosillo, R.; De La Fuente, D.; Priore, P. Blockchain in FinTech: A Mapping Study. Sustainability 2019, 11, 6366. [CrossRef]

30. Rabah, K. 2018. Convergence of AI, IoT, big data and blockchain: A review. Lake Inst. J. 2018, 1, 1-18.

31. Liu, L.; Li, F.; Qi, E. Research on Risk Avoidance and Coordination of Supply Chain Subject Based on Blockchain Technology. Sustainability 2019, 11, 2182. [CrossRef]

32. Rocha, G.d.S.R.; de Oliveira, L.; Talamini, E. Blockchain Applications in Agribusiness: A Systematic Review. Future Internet 2021, 13, 95. [CrossRef]

33. Markets and markets' Blockchain in Agriculture and Food Supply Chain Market by Application (Product Traceability, Payment and Settlement, Smart Contracts, and Governance, Risk and Compliance Management), Provider, Organization Size, and RegionGlobal Forecast to 2025. Available online: https:/ /www.marketsandmarkets.com/Market-Reports/blockchain-agriculturemarket-and-food-supply-chain-55264825.html (accessed on 17 August 2021).

34. Daniel, D.; Speranza, C.I. The Role of Blockchain in Documenting Land Users' Rights: The Canonical Case of Farmers in the Vernacular Land Market. Front. Blockchain 2020, 3, 19. [CrossRef]

35. Bechtsis, D.; Tsolakis, N.; Bizakis, A.; Vlachos, D. A Blockchain Framework for Containerized Food Supply Chains. Comput. Aided Chem. Eng. 2019, 46, 1369-1374.

36. Tao, Q.; Cui, X.; Huang, X.; Leigh, A.M.; Gu, H. Food Safety Supervision System Based on Hierarchical Multi-Domain Blockchain Network. IEEE Access 2019, 7, 51817-51826. [CrossRef]

37. Mao, D.; Hao, Z.; Wang, F.; Li, H. Novel Automatic Food Trading System Using Consortium Blockchain. Arab. J. Sci. Eng. 2019, 44, 3439-3455. [CrossRef]

38. Lin, J.; Shen, Z.; Zhang, A.; Chai, Y. Blockchain and IoT based Food Traceability for Smart Agriculture. In Proceedings of the 3rd ACM International Conference on Crowd Science and Engineering, Singapore, 28-31 July 2018; pp. 1-6.

39. Gatteschi, V.; Lamberti, F.; Demartini, C.; Pranteda, C.; Santamaría, V. Blockchain and Smart Contracts for Insurance: Is the Technology Mature Enough? Future Internet 2018, 10, 20. [CrossRef]

40. Cariolle, J.; Carroll, D. Advancing Digital Frontiers in African Economies: Lessons Learned from Firm-Level Innovations. FERDI Working Paper P281. 2020. Available online: https:/ / hal.archives-ouvertes.fr/hal-03118738/ (accessed on 21 September 2021).

41. Farshidi, S.; Jansen, S.; España, S.; Verkleij, J. Decision Support for Blockchain Platform Selection: Three Industry Case Studies. IEEE Trans. Eng. Manag. 2020, 67, 1109-1128. [CrossRef]

42. Lo, S.K.; Xu, X.; Chiam, Y.K.; Lu, Q. Evaluating Suitability of Applying Blockchain. In Proceedings of the IEEE 22nd International Conference on Engineering Complex Computer Systems, Fukuoka, Japan, 5-8 November 2017; pp. 158-161. 